\title{
Inovação e empreendedorismo: Uma análise lexical a partir de estudos científicos internacionais e nacionais brasileiros (2015-2019)
}

Innovation and entrepreneurship: A lexical analysis from international and Brazilian national scientific studies (2015-2019)

Innovación y emprendimiento: Un análisis léxico de estudios científicos internacionales y nacionales brasileños (2015-2019)

\begin{abstract}
Resumo
O presente artigo teve como finalidade apresentar uma revisão bibliográfica sistemática sobre o empreendedorismo e inovação a partir dos trabalhos científicos publicados em periódicos brasileiros e internacionais entre o período de 2015 e 2019 sob a perspectiva da análise lexical. Em termos metodológicos, realizou-se, primeiramente, a catalogação de estudos científicos em âmbitos nacional e internacional para os anos propostos e que contavam, dentre suas palavras-chave, os vocábulos inovação e empreendedorismo. Então, selecionaram-se quarenta estudos científicos nacionais e internacionais que foram codificados para realização da análise lexical com intermédio do software IRaMuteq (Interface de $\mathrm{R}$ pou les Analyses Multidimensionnelles de Textes et de Questionnaires). Os resultados revelam que o corpus textual foi categorizado em seis clusters. Os clusters 5 e 6 revelaram conexão entre si, assim como ocorreu os clusters 1 e 4. Assim, possibilitou-se identificar conexões entre os vocábulos "inovação" e "empreendedorismo" como elementos centrais para formar a rede de palavras e é interessante ressaltar que a o vocábulo "empreendedor" se mostra um ramo da palavra "inovação" e não da palavra "empreendedorismo" como era de se esperar.
\end{abstract}

Palavras-chave: Revisão sistemática; Inovação; Empreendedorismo; Software IRaMuteq.

\begin{abstract}
The present article aimed to present a systematic bibliographic review on entrepreneurship and innovation from scientific papers published in Brazilian and international journals between 2015 and 2019 from the perspective of lexical analysis. In methodological terms, the word innovation and entrepreneurship were first cataloged at national and international level for the years proposed and which counted, among its keywords, the words innovation and entrepreneurship. Forty national and international scientific studies were selected and then coded to perform a lexical analysis through the software IRaMuteq (Interface of $\mathrm{R}$ pou les Analyses Multidimensionnelles de Textes et de Questionnaires). The results reveal that the textual corpus was categorized into six clusters. Clusters 5 and 6 revealed a connection to each other, as did clusters 1 and 4 . Thus, it was possible to identify connections between the words "innovation" and "entrepreneurship" as central elements to form the word network and it is interesting to highlight that the word "entrepreneur" is shown to be a branch of the word "innovation" and not of the word "entrepreneurship" as expected.
\end{abstract}

Keywords: Systematic review; Innovation; Entrepreneurship; IRaMuteq software.

\section{Resumen}

Este estudio tuvo como objetivo realizar una revisión sistemática sobre emprendimiento e innovación a partir de trabajos científicos publicados en revistas brasileñas e internacionales entre los años 2015 y 2019 desde la perspectiva del análisis léxico. En cuanto a los aspectos metodológicos, se realizó una encuesta de artículos nacionales e 
internacionales entre los años 2015 y 2019 que tenía, entre sus palabras clave, las palabras innovación y emprendimiento. Posteriormente, se seleccionaron cuarenta artículos que fueron codificados para realizar el análisis léxico mediante el software IRaMuteq (Interface of $\mathrm{R}$ pou les Analyzes Multidimensionnelles de Textes et de Questionnaires). El resultado de la investigación revela que el corpus textual se dividió en seis grupos. Los clústeres 5 y 6 combinados revelan una conexión entre sí, tal como sucedió con los clústeres 1 y 4 . Con los resultados se pudo señalar conexiones entre las palabras "innovación" y "emprendimiento" como elementos centrales para formar la red de palabras y es interesante resaltar que la palabra "emprendedor" muestra una rama de la palabra "innovación "y no la palabra" Emprendimiento "como se esperaba.

Palabras clave: Revisión sistemática; Innovación; Emprendimiento; Software IRaMuteq.

\section{Introdução}

Pode-se dizer que é no século XX que o estudo da inteligência em Economia potencializa o seu protagonismo quando Joseph Alois Schumpeter publica, em 1911, sua obra Teoria do Desenvolvimento Econômico, e em seu capítulo 2, denominado O Fenômeno Fundamental do Desenvolvimento Econômico, atribui à inovação disruptiva um caráter central no fenômeno do desenvolvimento econômico (Schumpeter, 1997).

Todavia, a prática da inovação está intrinsecamente relacionada à outra prática, também muita cara a ciência econômica, qual seja: a de empreender. Como destaca Howkins (2013) foi o economista e jornalista francês Jean Baptiste Say (1767 - 1832) que cunhou o termo "entrepreneur (empreendedor) para descrever alguém que libera capital anteriormente imobilizado em terras e o redireciona para mudar o futuro. Ele foi, assim, um dos primeiros economistas a incorporar a ideia de mudança e incerteza como algo normal e até mesmo positivo".

Dentro deste contexto, é de grande valia estudos teóricos e/ou empíricos que busquem contribuir com o estado da arte da temática da inovação e do empreendedorismo tendo em vista a sua crescente importância como fatores que catalizam o desenvolvimento socioeconômico. Sendo assim, o objetivo geral deste trabalho é realizar uma revisão teórica sobre o tema inovação e empreendedorismo no cenário nacional e internacional para o período de 2015 a 2019. Simultaneamente, deseja-se identificar possíveis gaps teóricos relevantes para futuros estudos científicos.

A revisão sistemática foi selecionada para este trabalho por servir como fonte de investigação da literatura sobre um tema específico e gerar fontes de informações para tomada de decisão. Nesse tipo de revisão, os pesquisadores trabalham os dados de tal forma que outros estudiosos possam utilizar o resultado como auxílio em suas pesquisas, além de proporcionar um conjunto de evidências sobre um determinado tema que podem apresentar argumentos e resultados concordantes ou discordantes que sirvam de base para futuros estudos (Sampaio \& Mancini, 2007; Galvão \& Pereira, 2014).

Em relação à relevância e a contribuição que este estudo pode fornecer para a pesquisa cientifica, podem-se apontar dois motivos norteadores: o primeiro refere-se ao relativo ineditismo na utilização do software IRaMuteq para os estudos com a temática escolhida. E segundo, a importância que o estudo lexical proporciona a identificação de gaps teóricos que podem servir de auxílio aos estudos vindouros. No tocante aos artigos selecionados, foram objetos de pesquisa os periódicos brasileiros e internacionais encontrados na base de dados das seguintes instituições: Coordenação de Aperfeiçoamento de Pessoal de Nível Superior (CAPES) e ELSEVIER®, compreendendo o período de 2015 a 2019. Assim, ao final, foram selecionados quarenta (40) artigos.

Este trabalho é dividido em quatro seções incluindo esta introdução, que trata dos aspectos gerais e o resgate teórico da relação dos temas inovação e empreendedorismo. A seção seguinte trata dos aspectos metodológicos explica a utilização do software IRAMUTEQ para análise dos dados do corpus textual. Os resultados correspondem à seção quatro, em que são apresentados os dados obtidos por meio da utilização do software IRaMuteq. E finalmente, na seção cinco são realizadas as considerações finais. 


\subsection{Empreendedorismo e inovação: o que diz a literatura?}

O conceito de empreendedorismo foi estabelecido, pela primeira vez em 1700, e desde então vem evoluindo e demandado maior atenção e interesse na literatura e, nesse contexto, Richard Cantillon foi um dos primeiros a definir o ser empreendedor, que o considerou como aquele que compra os fatores de produção para a fabricação do bem ou serviços final que ele ofertará com um preço até então não determinado (Erenkol \& Oztas, 2015).

Consoante à inovação, este é um conceito intrínseco ao progresso técnico e que está presente em todas as abordagens teóricas que versam sobre crescimento e desenvolvimento econômico. Na linhagem teórica neoclássica, de raízes smithianas, o progresso técnico é suposto como exógeno aos modelos explicativos de crescimento econômico, cuja maior referência é Robert Solow (Jones, 1998). Tal suposição trouxe certo desconforto a teoria econômica e motivou a consolidação de uma nova linhagem de modelos explicativos do crescimento econômico propostos por Paul Romer na década de 1990, em que a hipótese da exogenia do progresso técnico foi substituída pela endogenia. Com isso, a economia das ideias - que abrange a inovação e o empreendedorismo - torna-se uma peça fundamental no quebra cabeça do crescimento econômico (Jones, 1998).

Porém, faz-se necessário destacar que as origens da hipótese de que o progresso técnico era endógeno ao crescimento econômico data no começo do século XX com Schumpeter (1997) quando da sua definição de desenvolvimento econômico. Para Schumpeter (1997 p. 75), o desenvolvimento econômico era "uma mudança espontânea e descontinua nos canais do fluxo, perturbação do equilíbrio, que altera e desloca para sempre o estado de equilíbrio previamente existente”. Na concepção schumpeteriana, o progresso tecnológico, que por meio das inovações provoca o que ele denominou de destruição criadora, é o responsável direto pelo fenômeno do desenvolvimento econômico.

É fato que o progresso técnico trouxe crescimento econômico e melhoria na qualidade de vida das populações do mundo. Contudo, a forma como este progresso técnico tem sido administrado e como os seus efeitos têm sido distribuídos pelo mundo ainda é bastante desigual, contribuindo para resultados bastante contraditórios em termos de bem-estar social, que são: a alta concentração de renda; a ainda existência da extrema pobreza e uso predatório dos recursos naturais (Steenbock et. al., 2013; Bouskela et. al, 2016).

$\mathrm{O}$ século XXI tem, portanto, estes três grandes desafios a serem enfrentados e alguns acontecimentos recentes tem mostrado a urgência na busca de soluções nestas três questões. A concentração de renda, sem dúvida é o fator que autoriza a existência da extrema pobreza, logo, estes dois problemas se resumem a um só: reduzir a concentração de renda para que as populações miseráveis tenham a possibilidade de acesso ao desenvolvimento sob a perspectiva da liberdade, como aponta Amartya Sen (1999). Para Sen, o desenvolvimento econômico vai além dos aspectos relativos ao PIB e a renda per capita, pois estaria associado às liberdades substantivas e instrumentais. As liberdades substantivas incluem: ter condições de evitar privações como a fome, a subnutrição, a morbidez evitável e a morte prematura, assim como saber ler e fazer cálculos aritméticos, ter participação política e liberdade de expressão, etc. E as liberdades instrumentais estão atreladas à liberdade política; às facilidades econômicas; às oportunidades sociais; às garantias de transparência e à segurança protetora.

Sob o prisma do empreendedorismo uma solução para mitigar a extrema pobreza foi proposta por Muhammad Yunus que, em 2006, ganhou o Nobel da Paz pelo seu trabalho na fundação do Grameen Bank. Este é um empreendimento social que tem no microcrédito - com prioridade para as mulheres - um modo de reduzir a pobreza no mundo (Yunus, 2000). No Brasil, a implementação do microcrédito com base na proposta do Grameen Bank foi feita via Banco do Nordeste do Brasil (BNB). Instituições menores ligadas ao crédito, tais como os bancos de moeda social, também são empreendimentos que contribuem de forma relevante para a redução da pobreza, como o trabalho pioneiro do Banco Palmas, localizado na periferia de Fortaleza, capital do Ceará, que ganhou destaque como elemento propulsor de empoderamento e gerador de emprego e renda para a população da comunidade local (Mostagi et al., 2019). 
A criação de empreendimentos sociais ou os negócios sociais, como denomina Yunus em seu livro "Criando um Negócio Social" tem sido referência para uma gama de empresas de médio e pequeno porte que vislumbram não apenas o lucro econômico, mas uma contribuição na perspectiva do coletivo social. Geralmente estes empreendimentos consideram o desenvolvimento econômico um fenômeno complexo, que não se reduz ao econômico, pois está atrelado ao social, ao cultural, ao institucional e ao ambiental.

Para Momete (2015), a essência do empreendedorismo baseia-se na autoconfiança, na confiança do valor das próprias ideias trazidas da educação e resiliência do agente que irá ser o instrumento de criação de um novo negócio. O autor complementa que a criação da cultura empreendedora se inicia com a educação superior, contudo dependerá, também, de fatores como respeito, seriedade, confiabilidade e responsabilidade. A educação surge, então, como elemento chave para o mundo globalizado porque proporciona conhecimento avançado e vantagem competitiva para os indivíduos e para o país. Harkema e Popescu (2015) contribuem com o debate ao enfatizar o papel decisivo que as instituições educacionais desempenham para o desenvolvimento de competências empresariais que levam, posteriormente, a capacidade empreendedora.

Como ressalta Metcalf (2003), para compreender o capitalismo contemporâneo e sua natureza incansável faz-se necessário assinalar a noção do empreendedor no que diz respeito à análise, pois este é o agente principal e crucial ao processo de gerar novos conhecimentos econômicos. Metcalfe enfatiza, também, que através das instituições do mercado, o empreendedorismo cria mais empreendedorismo e o conhecimento gera novos conhecimentos.

Por esse motivo, os governos dos países estão considerando e apoiando, via políticas governamentais, o empreendedorismo como necessário para impulsionar o crescimento econômico via geração de novas oportunidades de empregos na sociedade, além do crescimento da renda e redução da pobreza. A ideia defendida é que o empreendedorismo traz consigo o processo inovativo e originalidade para alavancar o desenvolvimento social e econômico. Assim, as empresas que consegue lançar-se no mercado com suas inovações obtêm lucratividade e posição de destaque neste mercado (Erenkol \& Oztas, 2015). Harkema e Popescu (2015) corroboram com esse argumento ao enfatizar que a inovação é primordial para o crescimento das empresas, enquanto que o empreendedorismo é o instrumento chave para o crescimento econômico interno de uma nação. Os autores complementam, ainda, que o empreendedorismo está relacionado à capacidade do empresário de transformar janelas de oportunidades em propostas interessantes, enquanto a inovação refere-se à materialização das oportunidades em mudanças, que pode ser em produtos, serviços ou mudanças organizacionais.

Em relação à tipologia do empreendedorismo, não existe unanimidade entre os autores. Segundo Leite e Oliveira (2007) existem dois tipos de Empreendedorismo: o Empreendedorismo por Necessidade (criam-se negócios por não haver outra alternativa) e o Empreendedorismo por Oportunidade (descoberta de uma oportunidade de negócio lucrativa). Nesse contexto, os empreendedores por necessidade iniciaram seu empreendimento de maneira autônoma, por não possuírem melhores opções para trabalho, e diante dessa situação, tem como objetivo a abertura de um negócio com o intuito de gerar renda para manter suas famílias (Moreira, 2010). Para Hisrich e Peters (2004), o empreendedorismo por necessidade está mais ligado à situação econômica dos países, cuja tendência para esse tipo é diminuir quando a oferta de emprego é maior, porém sendo mais praticado por pessoas em dificuldade financeira, cuja vulnerabilidade a estimulam a entrar nesse processo.

Também existe o termo intraempreendedoríssimo, termo que caracteriza as empresas que estimulam e incentivam as iniciativas empreendedoras de seus funcionários. O fim proposto pelo intraempreendedoríssimo é satisfazer a necessidade de inovação nas organizações, causando impreterivelmente o aumento da competitividade (Pinchot \& Pellman, 2004; Hashimoto, 2006). Dessa maneira, o intraempreendedoríssimo tem seu foco direcionado para cada funcionário da organização e sua capacidade de resolver problemas sozinho de forma empreendedora. $\mathrm{O}$ especialista desse tipo de empreendedorismo toma para si a função daquele funcionário que, dentro da organização, assume a responsabilidade de propiciar a inovação de qualquer tipo, a qualquer momento, em qualquer lugar da empresa (Hashimoto, 2006). 
Desta maneira, a inovação surge como instrumento a ser utilizado por diversos tipos de organizações e, para cada realidade vivenciada, os aspectos devem ser ressaltados a fim de promover ou mitigar as possíveis barreiras que possam dificultar essas realidades. Contudo, essa questão é complexa e envolve díspares entendimentos, dimensões e contextos de aplicação que, por consequência, são compreendidas sob diferentes abordagens teóricas em vários campos do conhecimento, ramos de atividade e setores industriais (Faria \& Fonseca, 2014). A inovação remete, portanto, a capacidade da empresa de se renovar, adaptar-se às novas circunstâncias e alterar seus procedimentos e estruturas para criar uma nova dinâmica de se trabalhar, onde a ausência inovativa leva a empresa à inércia e, provavelmente, a sua não sobrevivência (Harkema \& Popescu, 2015). Para Schumpeter, a inovação é reflexo do resultado de atividades criativas, o que constitui, por sua vez, a essência da definição de empreendedorismo (Schumpeter, 1997; Erenkol \& Oztas, 2015).

\section{Aspectos metodológicos}

\subsection{Origem dos dados e espaço temporal da pesquisa}

Para a elaboração deste trabalho, foram utilizados os resumos de 40 artigos no total, sendo 20 artigos de periódicos brasileiros e 20 artigos internacionais encontrados na base de dados das seguintes instituições: Coordenação de Aperfeiçoamento de Pessoal de Nível Superior (CAPES) e ELSEVIER® que tiveram seus resumos traduzidos (Figura 1). Assim, esta pesquisa caracteriza-se como estudo bibliográfico a partir dos trabalhos selecionados nas duas plataformas de pesquisa citadas, onde, mesclaram-se aspectos qualitativos e quantitativos em sua análise. Como aponta Köche (2011, p.122): "a pesquisa bibliográfica é a que se desenvolve tentando explicar um problema, utilizando o conhecimento disponível a partir das teorias publicadas em livros ou obras congêneres". Trata-se, também, de uma pesquisa de abordagem quantitativa, pois, por meio da análise lexical, busca-se exprimir informações em número para classificá-las e analisá-las (Prodanov \& Freitas, 2013).

Figura 1: Desenho metodológico da pesquisa.

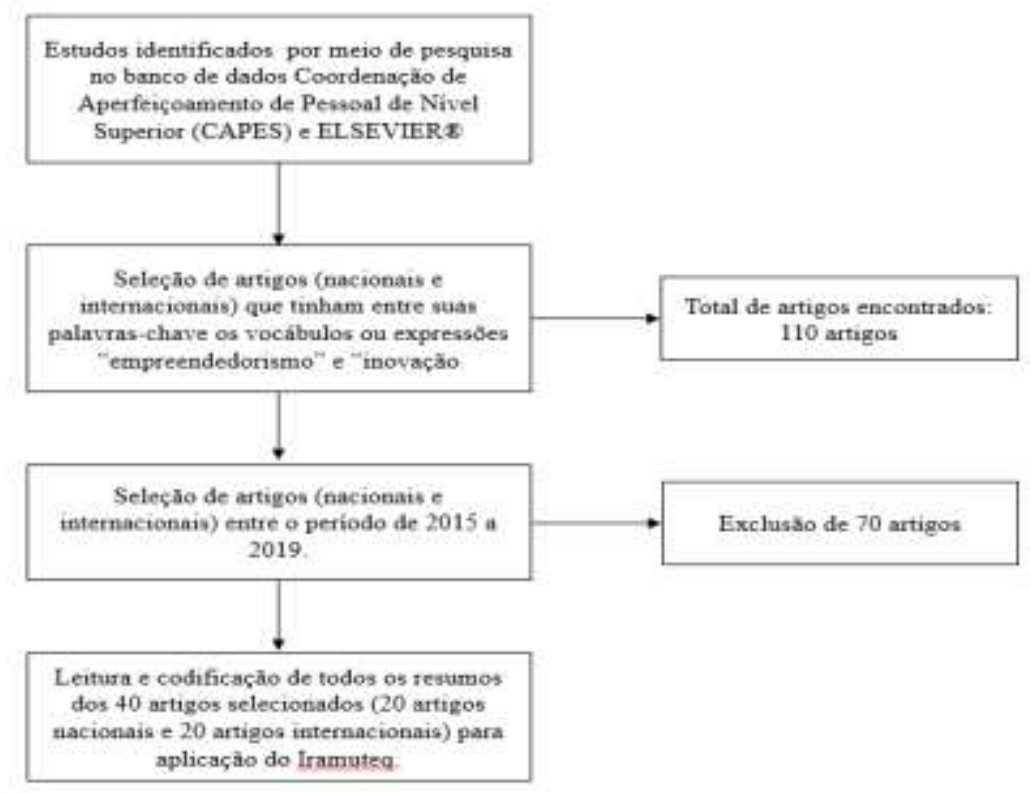

Fonte: Autores (2020).

Em síntese, os resumos de todos os artigos foram lidos e agrupados em um único arquivo de texto para compor o material de análise. Dessa maneira, foram realizados leituras, aprimoramentos e deciframentos para não interferir no propósito 
do estudo de maneira negativa e para se adquirirem melhores resultados, onde os erros foram levados ao mínimo para as análises e interpretações. Os critérios utilizados para a seleção dos artigos, que fazem parte do corpus de análise, foram: a) artigos aplicados ao empreendedorismo e inovação, em que as palavras-chave fossem "empreendedorismo" e "inovação"; b) artigos oferecidos online nos periódicos nacionais, internacionais, em português e em inglês; c) horizonte temmporal de 2015 a 2019 (Tabela 1).

Tabela 1: Artigos selecionados para compor o corpus de análise do artigo.

\begin{tabular}{c|c|c|c}
\hline \multirow{2}{*}{ Artigos } & Autor (es) & Título & Periódico/Ano \\
\hline
\end{tabular}

\section{Artigos internacionais}

\begin{tabular}{|c|c|c|c|}
\hline Artigo_1 & Eric Joseph Van Holm & Makerspaces and Contributions to Entrepreneurship & $\begin{array}{c}\text { Procedia - Social and } \\
\text { Behavioral Sciences (2015) }\end{array}$ \\
\hline Artigo_2 & Letycja Sołoducho-Pelc & $\begin{array}{l}\text { Searching for opportunities for development and } \\
\text { innovations in the strategic management process }\end{array}$ & $\begin{array}{c}\text { Procedia - Social and } \\
\text { Behavioral Sciences (2015) }\end{array}$ \\
\hline Artigo_3 & Daniela Cristina Momete & $\begin{array}{l}\text { Joining economic and engineering perspectives }-\mathrm{a} \\
\text { tool for successful entrepreneurs }\end{array}$ & $\begin{array}{c}\text { Procedia - Social and } \\
\text { Behavioral Sciences (2015) }\end{array}$ \\
\hline Artigo_4 & $\begin{array}{l}\text { H. Anil Degermen Erenkol; Burçak Boydak } \\
\text { Oztas }\end{array}$ & Entrepreneurial Brand & $\begin{array}{c}\text { Procedia - Social and } \\
\text { Behavioral Sciences (2015) }\end{array}$ \\
\hline Artigo_5 & Srivardhini K. Jha & $\begin{array}{l}\text { Entrepreneurial ecosystem in India: Taking stock and } \\
\text { looking ahead }\end{array}$ & $\begin{array}{l}\text { IIMB Management Review } \\
\text { (2018) }\end{array}$ \\
\hline Artigo_6 & Daniela Damian; Ciprian Manea & $\begin{array}{l}\text { Causal recipes for turning fin-tech freelancers into } \\
\text { smart entrepreneurs }\end{array}$ & $\begin{array}{l}\text { Journal of Innovation \& } \\
\text { Knowledge (2019) }\end{array}$ \\
\hline Artigo_7 & Saskia Harkemaa; Florentin Popescu & "Entrepreneurship education for adults: a case-study" & $\begin{array}{c}\text { Procedia - Social and } \\
\text { Behavioral Sciences (2015) }\end{array}$ \\
\hline Artigo_8 & $\begin{array}{l}\text { Luiz Stephany Filho; Elda Fontinele } \\
\text { Tahima; Vitória Maria Serafima; Cynara } \\
\text { Barros de Moraes }\end{array}$ & $\begin{array}{l}\text { From invention to Innovation-challenges and } \\
\text { opportunities: a multiple case study of independent } \\
\text { inventors in Brazil and Peru }\end{array}$ & $\begin{array}{c}\text { IMR Inovation \& } \\
\text { Management Review (2017) }\end{array}$ \\
\hline Artigo_9 & Adriana Bujor; Silvia Avasilcai & The Creative Entrepreneur: a Framework of Analysis & $\begin{array}{c}\text { Procedia - Social and } \\
\text { Behavioral Sciences (2016) }\end{array}$ \\
\hline Artigo_10 & Paul K Collins & $\begin{array}{l}\text { Building A Local Design And Entrepreneurship } \\
\text { Ecosystem }\end{array}$ & $\begin{array}{c}\text { Procedia - Social and } \\
\text { Behavioral Sciences (2015) }\end{array}$ \\
\hline Artigo_11 & Elena Harpa & $\begin{array}{l}\text { Macroeconomic Analysis of the Competitive Factors } \\
\text { which Influence Innovation in Rural Entrepreneurship }\end{array}$ & $\begin{array}{c}\text { Procedia - Social and } \\
\text { Behavioral Sciences (2017) }\end{array}$ \\
\hline Artigo_12 & Harpa Helena; Moica Sorina; Dana Rus & $\begin{array}{l}\text { A predictive modelo } \mathrm{f} \text { innovation in rural } \\
\text { entrepreneurship }\end{array}$ & $\begin{array}{c}\text { Procedia - Social and } \\
\text { Behavioral Sciences (2015) }\end{array}$ \\
\hline Artigo_13 & $\begin{array}{l}\text { Tatyana Shindina; Yevgeniy Lysenko; Nina } \\
\text { Orlova }\end{array}$ & $\begin{array}{l}\text { Entrepreneurs' Training in Innovation-Oriented } \\
\text { Society }\end{array}$ & $\begin{array}{c}\text { Procedia - Social and } \\
\text { Behavioral Sciences (2015) }\end{array}$ \\
\hline Artigo_14 & $\begin{array}{l}\text { Cesar Bandera; Fazel Keshtkar; Michael R. } \\
\text { Bartolacci; Shiromani Neerudu; Katia } \\
\text { Passerini }\end{array}$ & $\begin{array}{l}\text { Knowledge management and the entrepreneur: } \\
\text { Insights from Ikujiro Nonaka's Dynamic Knowledge } \\
\text { Creation model (SECI) }\end{array}$ & $\begin{array}{l}\text { International Journal of } \\
\text { Innovation Studies (2017) }\end{array}$ \\
\hline
\end{tabular}


Tabela 1: Artigos selecionados para compor o corpus de análise do artigo.

\begin{tabular}{|c|c|c|c|}
\hline Artigos & Autor (es) & Título & Periódico/Ano \\
\hline Artigo_15 & Elyase Iskender; Gulgonul Bozoglu Bati & $\begin{array}{l}\text { Comparing Turkish Universities Entrepreneurship and } \\
\text { Innovativeness Index's Rankings with Sentiment } \\
\text { Analysis Results on Social Media }\end{array}$ & $\begin{array}{l}\text { International Journal of } \\
\text { Innovation Studies (2015) }\end{array}$ \\
\hline Artigo_16 & Yavuz Çingitas; Zumrut Ecevit Sati & $\begin{array}{l}\text { Economic and Social Benefits that can be obtained by } \\
\text { a Combination of Innovation and Corporate } \\
\text { Entrepreneurship Activities in Turkish Companies }\end{array}$ & $\begin{array}{l}\text { International Journal of } \\
\text { Innovation Studies (2015) }\end{array}$ \\
\hline Artigo_17 & Evrim Kabukcu & $\begin{array}{l}\text { Creativity process in innovation oriented } \\
\text { entrepreneurship: The case of Vakko }\end{array}$ & $\begin{array}{l}\text { International Journal of } \\
\text { Innovation Studies (2015) }\end{array}$ \\
\hline Artigo_18 & Chirantan Chatterjee; Swapnika Ramu & $\begin{array}{l}\text { Gender and its rising role in modern Indian innovation } \\
\text { and entrepreneurship }\end{array}$ & $\begin{array}{l}\text { IIMB Management Review } \\
\qquad(2018)\end{array}$ \\
\hline Artigo_19 & $\begin{array}{l}\text { Jonathan Servoss; Connie Chang; David } \\
\text { Olson; Kevin R. Ward; Michael W. } \\
\text { Mulholland, MD; Mark S. Cohen }\end{array}$ & $\begin{array}{l}\text { The Surgery Innovation and Entrepreneurship } \\
\text { Development Program (SIEDP): An Experiential } \\
\text { Learning Program for Surgery Faculty to Ideate and } \\
\text { Implement Innovations in Health care }\end{array}$ & $\begin{array}{l}\text { Journal of Surgical Education } \\
\qquad(2017)\end{array}$ \\
\hline Artigo_20 & $\begin{array}{l}\text { Jorge Gámez Gutiérrez; Jossie Esteban } \\
\text { Garzón Baquero }\end{array}$ & $\begin{array}{l}\text { New cross-proposal entrepreneurship and innovation } \\
\text { in educational programs in third level (tertiary) } \\
\text { education }\end{array}$ & $\begin{array}{l}\text { Contaduría y Administración } \\
\text { (2017) }\end{array}$ \\
\hline
\end{tabular}

\section{Artigos nacionais}

\begin{tabular}{|c|c|c|c|}
\hline Artigo_21 & $\begin{array}{l}\text { Cláudio Roberto Leandroa; João Amato } \\
\text { Neto }\end{array}$ & $\begin{array}{l}\text { Uma abordagem cognitiva sobre o processo de } \\
\text { institucionalização de sistemas locais de produção e } \\
\text { inovação }\end{array}$ & Production (2015) \\
\hline Artigo_22 & Jorge Lami; Silvia Fernandes; Eric Vaz & $\begin{array}{l}\text { A governação em SI: o caso da gestão das convenções } \\
\text { e acordos de saúde do Algarve }\end{array}$ & $\begin{array}{c}\text { Revista lbérica de Sistemas e } \\
\text { Tecnologias de Informação } \\
\text { (2015) }\end{array}$ \\
\hline Artigo_23 & Tiago Hideki Niwa & $\begin{array}{l}\text { Inovação e Empreendedorismo à Luz de Teorias de } \\
\text { Políticas Públicas }\end{array}$ & $\begin{array}{l}\text { Revista de Políticas Públicas } \\
\text { (2017) }\end{array}$ \\
\hline Artigo_24 & $\begin{array}{l}\text { Maria Manuela Natário; Ascensão Martins } \\
\text { Braga; Gonçalo Poeta Fernandes }\end{array}$ & $\begin{array}{l}\text { Determinantes do desempenho empreendedor e } \\
\text { inovador nas regiões transfronteiriças }\end{array}$ & Innovar (2017) \\
\hline Artigo_25 & Tiago Hideki Niwa & $\begin{array}{l}\text { Exercício de análise de políticas públicas: o Programa } \\
\text { Estratégico para o Empreendedorismo e Inovação do } \\
\text { Governo de Portugal (Programa }+\mathrm{e}+\mathrm{i})\end{array}$ & $\begin{array}{l}\text { Revista Brasileira de Políticas } \\
\text { Públicas e Internacionais } \\
\text { (2017) }\end{array}$ \\
\hline Artigo_26 & $\begin{array}{l}\text { Anna Gabriela Miranda de Oliveira; } \\
\text { Marlene Catarina de Oliveira Lopes Melo; } \\
\text { Cristiana Fernandes de Muylder }\end{array}$ & $\begin{array}{l}\text { Educação Empreendedora: O Desenvolvimento do } \\
\text { Empreendedorismo e Inovação Social em Instituições } \\
\text { de Ensino Superior }\end{array}$ & $\begin{array}{l}\text { Revista Administração em } \\
\text { Diálogo (2015) }\end{array}$ \\
\hline Artigo_27 & $\begin{array}{l}\text { Marja Laurikainen; Flavio Lopes da Silva; } \\
\text { Paula Felipe schlemper; José Wlamir } \\
\text { Barreto Soares; Luis Henrique Mendes de } \\
\text { Melo }\end{array}$ & $\begin{array}{l}\text { Educação em Empreendedorismo: O que Podemos } \\
\text { Aprender dos Exemplos Brasileiros e Finlandeses? }\end{array}$ & $\begin{array}{l}\text { Revista Ibero-Americana de } \\
\text { Estudos em Educação (2018) }\end{array}$ \\
\hline
\end{tabular}


Tabela 1: Artigos selecionados para compor o corpus de análise do artigo.

\begin{tabular}{|c|c|c|c|}
\hline Artigos & Autor (es) & Título & Periódico/Ano \\
\hline Artigo_28 & $\begin{array}{l}\text { Thatiana Stacanelli Teixeira; Daniela } \\
\text { Meirelles Andrade; Valderí de Castro } \\
\text { Alcântara; Naiara Kasmin de Oliveira }\end{array}$ & $\begin{array}{l}\text { Inovação e Empreendedorismo: Um Caso no Setor } \\
\text { Público }\end{array}$ & Pretexto (2018) \\
\hline Artigo_29 & $\begin{array}{l}\text { Glauco Tapijara Vallicelli Nobrega; Daniel } \\
\text { de Cerqueira Lima; Penalva Santos; Andréa } \\
\text { Pereira da Silva }\end{array}$ & $\begin{array}{l}\text { Despertando o espírito empreendedor na educação } \\
\text { tecnológica: a realização de atividades para fomento } \\
\text { do empreendedorismo no CefetRJ/Câmpus Angra dos } \\
\text { Reis }\end{array}$ & $\begin{array}{l}\text { Caminho Aberto - Revista de } \\
\text { Extensão do IFSC (2018) }\end{array}$ \\
\hline Artigo_30 & $\begin{array}{l}\text { Juliana Cristina Gallas; Sandra Martins } \\
\text { Lohn Vargas; Fernando César Lenzi }\end{array}$ & $\begin{array}{l}\text { A Indústria de Cosméticos Sob a Perspectiva do } \\
\text { Empreendedorismo e da Capacidade Dinâmica }\end{array}$ & $\begin{array}{l}\text { Revista Eletrônica de } \\
\text { Estratégia \& Negócios (2015) }\end{array}$ \\
\hline Artigo_31 & 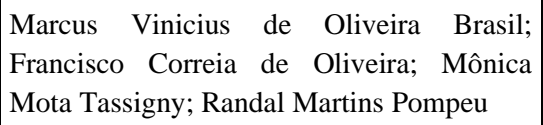 & $\begin{array}{l}\text { Inovações Sustentáveis em Projetos de } \\
\text { Responsabilidade Social }\end{array}$ & $\begin{array}{l}\text { Revista Eletrônica Gestão \& } \\
\text { Sociedade (2015) }\end{array}$ \\
\hline Artigo_32 & $\begin{array}{l}\text { Alex Fernando Borges; Mozar José de } \\
\text { Brito; Juvêncio Braga de Lima; Carolina } \\
\text { Lescura de Carvalho Castro }\end{array}$ & $\begin{array}{l}\text { Empreendedorismo em Empresas Familiares: A } \\
\text { Pesquisa Atual e os Desafios Futuros }\end{array}$ & $\begin{array}{l}\text { Revista ADM. Mackenzie } \\
\text { (2016) }\end{array}$ \\
\hline Artigo_33 & $\begin{array}{l}\text { Ricardo Augusto Bonotto Barboza; João } \\
\text { Bosco Faria }\end{array}$ & $\begin{array}{l}\text { Inovação em Pequena Empresa: um Estudo com } \\
\text { Produtores de Cachaça }\end{array}$ & $\begin{array}{l}\text { Revista Ciência em Extensão } \\
\text { (2015) }\end{array}$ \\
\hline Artigo_34 & Luciana Gehlen & $\begin{array}{l}\text { Empreendedorismo Corporativo - Aspectos de } \\
\text { Inovação e Mudança Organizacional }\end{array}$ & $\begin{array}{l}\text { Gestão e Desenvolvimento } \\
\qquad(2015)\end{array}$ \\
\hline Artigo_35 & Bruno Miguel Sousa & $\begin{array}{l}\text { A dinâmica diferenciadora e o processo de criação na } \\
\text { gestão de destinos turísticos }\end{array}$ & $\begin{array}{c}\text { Revista Brasileira de Pesquisa } \\
\text { em Turismo (2016) }\end{array}$ \\
\hline Artigo_36 & $\begin{array}{l}\text { Viviane Brandão Miguez; Álvaro } \\
\text { Guillermo Rojas Lezana }\end{array}$ & $\begin{array}{l}\text { Empreendedorismo e inovação: a evolução dos fatores } \\
\text { que influenciam o empreendedorismo corporativo }\end{array}$ & $\begin{array}{c}\text { Navus - Revista de Gestão e } \\
\text { Tecnologia (2017) }\end{array}$ \\
\hline Artigo_37 & $\begin{array}{l}\text { Eliana Andréa Severo; Julio Cesar Ferro } \\
\text { Guimarães; Vanessa Faedo Serafin; Mauro } \\
\text { Sergio Vanin }\end{array}$ & $\begin{array}{l}\text { Vamos Expandir um Negócio Inovador? Caso de } \\
\text { Ensino }\end{array}$ & $\begin{array}{l}\text { Revista de Administração, } \\
\text { Sociedade e Inovação (2019) }\end{array}$ \\
\hline Artigo_38 & $\begin{array}{l}\text { Eliana Maria dos Santos Pereira Alves; } \\
\text { Ovidio Felippe Pereira da Silva Júnior }\end{array}$ & $\begin{array}{l}\text { Aplicação da Criatividade para Gerar Projetos de } \\
\text { Inovação: O Caso Prático de uma Estratégia Didática }\end{array}$ & $\begin{array}{l}\text { Future Studies Research } \\
\text { Journal (2015) }\end{array}$ \\
\hline Artigo_39 & Sandro Alves de Medeiros & $\begin{array}{l}\text { Empreendedorismo Inovador: os valores e as } \\
\text { motivações dos microempreendedores da cidade de } \\
\text { Penedo-Alagoas }\end{array}$ & $\begin{array}{l}\text { Revista das Faculdades } \\
\text { Integradas Vianna Júnior } \\
\qquad(2015)\end{array}$ \\
\hline Artigo_40 & C.C.Webber; F.P.Nunes; J.C.F.Guimarães & $\begin{array}{l}\text { O Posicionamento Estratégico como Determinante do } \\
\text { Futuro de uma Indústria de Móveis: Caso de Ensino }\end{array}$ & $\begin{array}{c}\text { Revista Produção e } \\
\text { Desenvolvimento (2016) }\end{array}$ \\
\hline
\end{tabular}

Fonte: Autores (2020).

\subsection{Procedimentos de análise: técnicas utilizadas}

A análise de dados lexicais foi fundamentada em software que proporciona a quantificação e resultados estatísticos sobre elementos qualitativos, no caso os textos analisados (Camargo \& Justo, 2013). Dessa maneira, ao considerar a 
subjetividade do material coletado e o grande volume dos dados textuais, faz-se necessária a utilização de software de análise textual em pesquisas qualitativas (Gibbs, 2009). Portanto, o trabalho principal no qual este estudo está baseado foi o desenvolvido por Camargo e Justo (2013).

Conforme Camargo e Justo (2013), ao tomar como base os enunciados iniciais dos textos, por exemplo, consegue-se diferenciar as palavras e analisá-las entre si, principalmente quanto à sua maneira de distribuição e organização, de forma breve e organizada. Assim, segundo os autores, o software IRaMuteq é uma ferramenta apropriada para alcançar os objetivos da análise lexical, além de fornecer várias interpretações de dados textuais, que são: análise de especificidades, método da Classificação Hierárquica Descendente (CHD), análise de similitude e nuvem de palavras. Os autores afirmam, ainda, que o programa permite várias maneiras de análise de dados textuais, desde as mais simples até as mais complexas.

Dada estas características, o software IRaMuteq foi desenvolvido inicialmente por Pierre Ratinaud de forma bem similar ao funcionamento do software ALCESTE, com resultados comparáveis entre si. Contudo, segundo Smallman (2016), o IRAMUTEQ possui algumas vantagens por utilizar a linguagem de computador $\mathrm{R}$ com a realização de cálculos bem específicos a partir da incorporação de maiores informações, além de possibilitar a geração de gráficos das análises.

De acordo com Delattre et al. (2015), o IRaMuteq proporciona, ainda, a classificação e os vínculos existentes entre os vocábulos analisados por meio de medidas de proximidade. Assim, conforme os autores, o software identifica os termos como formas ativas (substantivos, verbos, adjetivos) e como formas complementares (artigos, preposições, funções), sendo apenas o primeiro grupo utilizado nas análises. Assim, diante das vantagens apresentadas, Camargo e Justo (2013) colocam que o uso do IRaMuteq no Brasil se iniciou a partir de 2013 com sua aplicação em trabalhos na área social e de saúde, dada sua contribuição para divulgação de dados qualitativos, o que vem ganhando notoriedade em diversas outras áreas de pesquisa.

Para a obtenção dos resultados desta pesquisa foram utilizadas as análises Classificação Hierárquica Descendente (CHD), Análise Fatorial de Correspondência (AFC) e Análise de Similitude. Em relação ao método da Classificação Hierárquica Descendente (CHD), Camargo e Justo (2013. P. 515) afirmam que "proposto por Reinert (1990) e utilizado pelo software ALCESTE classifica os segmentos de texto em função dos seus respectivos vocabulários, e o conjunto deles é repartido com base na frequência das formas reduzidas (palavras já lematizadas)."

A Análise Fatorial de correspondência é produzida a partir da CHD que representa num plano cartesiano os diversos vocábulos e os fatores associados a cada uma das classes da CHD (Camargo \& Justo, 2013). Por fim, foi utilizada a Análise de Similitude, que toma como referência a teoria dos grafos, o qual proporciona identificar as coocorrências entre os vocábulos e seu resultado. Nesse momento observa-se a conexão entre as palavras, ajudando no reconhecimento da estrutura de um corpus textual.

$\mathrm{Na}$ análise do artigo, foram utilizadas somente as formas ativas do corpus textual, a saber: substantivos, adjetivos, advérbios, verbos e nomes não comuns, que se referem às expressões importantes na análise, tais como inovação e empreendedorismo. Ou seja, omitiram-se outras formas, por exemplo, pronomes e formas complementares. A separação foi necessária para obter as palavras mais significantes para análise, além de eliminar o risco de uma grande quantidade de palavras o que poderia gerar falta de clareza.

\section{Resultados e Discussão}

Entre os quarenta (40) artigos analisados, o software IRaMuteq identificou a separação do corpus em 40 unidades de texto iniciais (UCE'S), 179 segmentos de textos (ST), 1.882 formas distintas e 6.470 ocorrências de palavras no texto. As formas mais utilizadas acima de 30 repetições foram: os substantivos (580 no total do corpus), com ênfase para as ocorrências: inovação (76 repetições), empresa (43) e estudo (37); os adjetivos corresponderam a 272 do total do corpus, com ênfase para as ocorrências acima de 15 repetições: empreendedor (59 repetições), novo (26) e inovador (33); em relação aos verbos, 
constataram-se 259, sendo os mais representativos (aqueles com mais de 10 repetições em todo o corpus): analisar (13 repetições), identificar, criar e apresentar, com 11 repetições cada um; por fim, em seguida, têm-se os advérbios com 58 aparições, cujos vocábulos que apresentaram acima de 10 repetições foram: como (57), mais (20) e também (12). Dos 179 segmentos de texto foram retidos 159 , isto é, $88,83 \%$ do universo de palavras, o qual está acima do percentual aceito para uma análise apropriada do corpus textual, que corresponde a 75\% (Moura, et al., 2014).

No que se refere à análise do corpus textual foi originado um dendrograma a partir da análise de CHD, com seis classes (Figura 2), o que permite analisar as proximidades e distanciamentos entre as classes criadas e delinear explicações sobre as criações de cada classe. Nesse cenário, existem duas formas de começar a análise; i) procura-se o grupo de classes unidas em maior porcentagem, assim sendo, elas abordam a maior parte do corpus a ser investigado ii) a presença de uma ou mais classes solitárias, que apresenta uma situação extraordinária inviabilizando até a análise daquela classe por meio de um método de comparação com outras, neste trabalho em específico, não se observa a existência de classe nesta forma. Se faz necessário que a leitura do dendrograma aconteça da esquerda para direita de acordo com as proximidades entre as classes para que seja realizada a leitura correta.

Figura 2: Classificação Hierárquica Descendente (CHD).

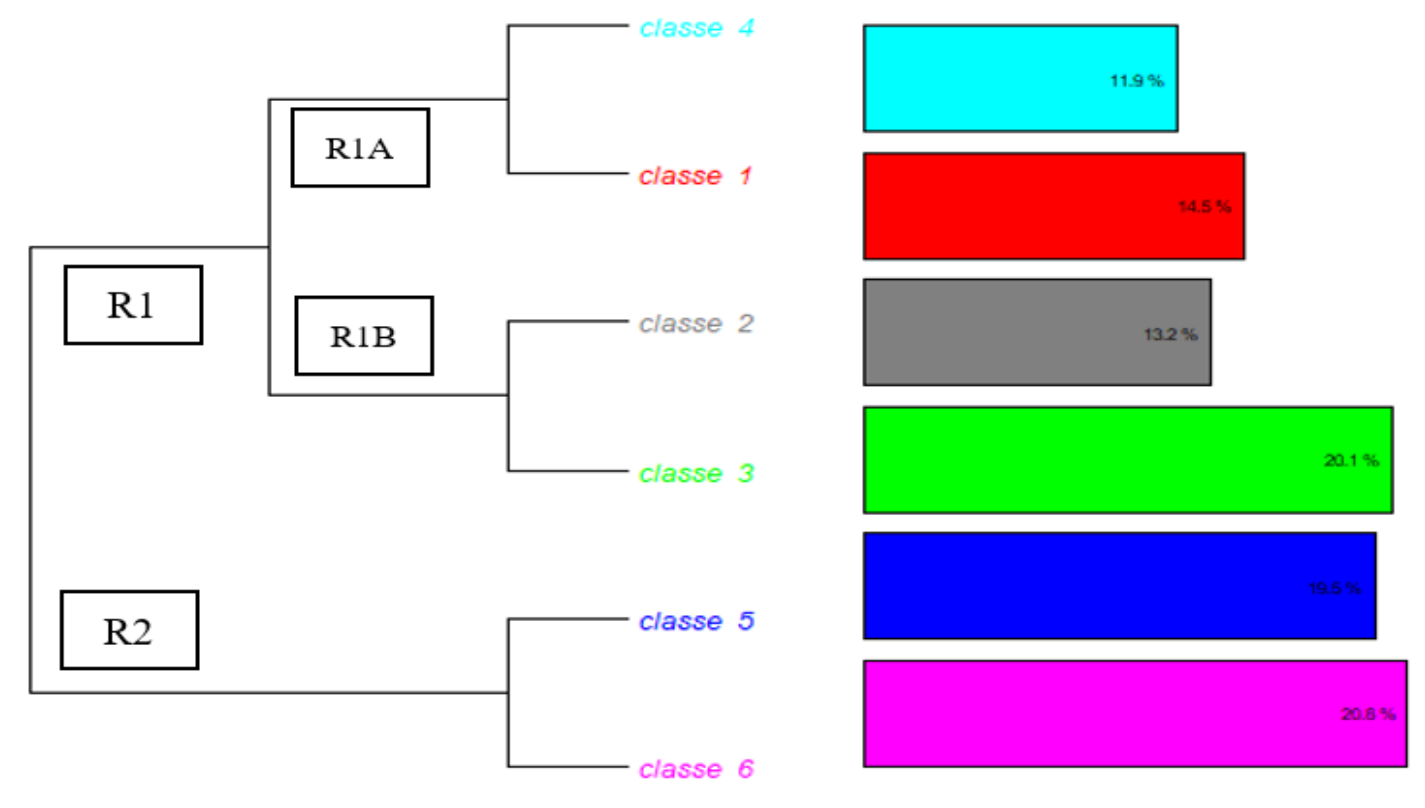

Fonte: Resultado da pesquisa a partir do software IRaMuteq. Elaboração própria (2020).

Os seis clusters ficaram divididos em dois sub-corpus (R1 e R2). O sub-corpus R1 foi dividido em mais dois subcorpus (R1A e R1B). A classe 1 (vermelho), pertence ao sub-corpus R1A, representando 14,5\% de participação no total do corpus textual e a classe 4 (azul claro) corresponde a 11,9\% e, juntas, representam 26,4\% do total do corpus. A classes 2 (cinza), representa 13,2\% do corpus textual e a classe 3 (verde) apresenta 20,1\%. Dessa forma, o sub-corpus R1B representa, ao todo, 33,3\% do corpus textual. A classe 5 (azul escuro), pertence ao sub-corpus R2, assim como a classe 6 (rosa), representando cada uma, respectivamente, $19,5 \%$ e $20,8 \%$ do total do corpus. É importante salientar que a conexão contextual cresce de forma diretamente proporcional à proximidade entres as classes, onde, na criação das categorias finais, existe a possibilidade de agrupamentos futuros (Camargo \& Justo, 2013). Isso posto, constata-se, primeiramente, que os artigos que formam as classes 4 e 1, por exemplo, estão, de alguma forma, ligados no que diz respeito a discussão da temática analisada, o 
mesmo acontecendo no grupo de artigos que constituem as classes 2 e 3 , e as classes 5 e 6 . A segunda informação que pode ser obtida da análise CHD é que as classes 4, 1, 2 e 3 ao mesmo tempo que estão na mesma raiz analítica tendem a dialogar entre si, o que não acontece com aqueles artigos que formam as classes 5 e 6 , pois estão em uma raiz analítica mais distante.

O Quadro 1 apresenta as classes antes vistas no dendrograma, em que foi partilhado o corpus textual por trabalhos com maior quantidade de semelhanças entre si e por grupos de autores. Assim, verifica-se que na classe 1 estão os trabalhos que tratam sobre a inovação na gestão de resultados, tanto nas empresas familiares, quanto em grandes corporações. Também se observam trabalhos que abordam a relação do estado com o empreendedorismo e como tal atividade pode ser um recurso a mais para o desenvolvimento social.

Quadro 1: Artigos selecionados que formam o Corpus de textos segundo suas classes

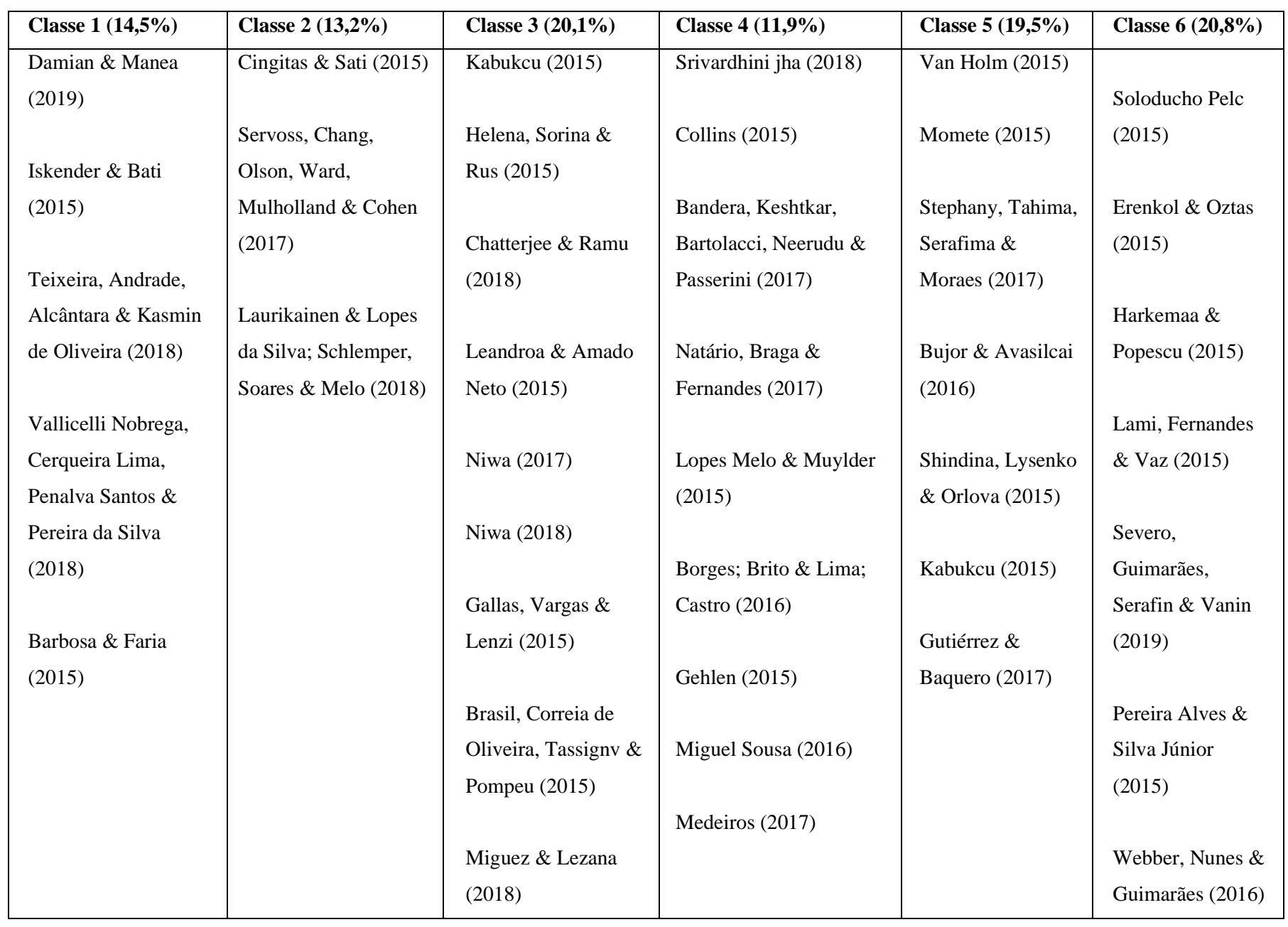

Fonte: Resultado da pesquisa a partir do software IRaMuteq. Elaboração própria (2020).

$\mathrm{Na}$ classe 2, deparou-se com estudos que discorrem sobre os benefícios econômicos e sociais que podem ser obtidos por uma combinação de atividades de inovação e empreendedorismo corporativo em empresas turcas, ou programas de aprendizagens experimentais de instituições de ensino para idealizar e implementar inovações na área da saúde, ou ainda, como podemos tirar proveito dos exemplos brasileiros e finlandeses com relação à educação em empreendedorismo. A classe 3, no que lhe diz respeito, reúne trabalhos acadêmicos que abordam: empreendedorismo rural; gênero e seu crescente papel na inovação e no empreendedorismo indiano moderno; exercício de análise de políticas públicas para o programa estratégico de 
empreendedorismo e inovação do governo de Portugal; e a indústria de cosméticos em relação ao empreendedorismo e sua capacidade dinâmica.

$\mathrm{Na}$ classe 4, ocorreu o agrupamento de artigos científicos que versam sobre a construção de ecossistema local de design e empreendedorismo na Austrália; a gestão do conhecimento e o empreendedor; determinantes do desempenho empreendedor e inovador nas regiões transfronteiriças do Brasil; o desenvolvimento do empreendedorismo e inovação social em instituições de ensino superior brasileiras. Na classe 5 estão os trabalhos que tratam sobre: espaços decisivos e contribuições para o empreendedorismo; da invenção à inovação - desafios e oportunidades: um estudo de caso múltiplo de inventores independentes no Brasil e no Peru; processo de criatividade no empreendedorismo orientado para a inovação; e o novo empreendedorismo entre propostas e inovação em programas educacionais no ensino superior.

Na classe 4 ocorreu o agrupamento de artigos científicos que versam sobre a construção de ecossistema local de design e empreendedorismo na Austrália; a gestão do conhecimento e o empreendedor; determinantes do desempenho empreendedor e inovador nas regiões transfronteiriças do Brasil; o desenvolvimento do empreendedorismo e inovação social em instituições de ensino superior brasileiras. Na classe 5 estão os trabalhos que tratam sobre: espaços decisivos e contribuições para o empreendedorismo; da invenção à inovação - desafios e oportunidades: um estudo de caso múltiplo de inventores independentes no Brasil e no Peru; processo de criatividade no empreendedorismo orientado para a inovação; e o novo empreendedorismo entre propostas e inovação em programas educacionais no ensino superior.

Por fim, na classe 6 houve a concentração de artigos científicos que aludem a: busca de oportunidades de desenvolvimento e inovações no processo de gestão estratégica; educação de empreendedorismo para adultos; aplicação da criatividade para gerar projetos de inovação; o posicionamento estratégico como determinante no futuro da indústria de móveis.

Desta maneira, aplicou-se a análise fatorial, que é uma técnica de análise multivariada, do qual se extraiu cinco fatores, destes os dois primeiros respondem por $46,43 \%$ do total da variância dos vocábulos. Essa técnica fornecida pelo IRaMuteQ é importante para ordenar e reduzir o quantitativo de variáveis correlacionadas entre si por meio da geração de fatores, denominados de componentes principais, o que auxilia na explicação da variabilidade do conjunto do texto. No caso da análise textual, método escolhido neste trabalho, as variáveis analisadas são os vocábulos presentes no corpus textual que formam as classes encontradas. Dessa forma, tem-se Fator 1, que representou 25,58\% da variância total dos vocábulos de corpus textual analisado, as quais revelaram aspectos importantes com relação à temática inovação e empreendedorismo. Enquanto que o Fator 2 explica 20,85\% da variabilidade total (vide Tabela 2). Esse processo de análise é importante para identificar, ainda, quais são as variáveis (vocábulos) que pertencem aos respectivos fatores.

Tabela 2: Autovalores e percentagem da variância total explicada pelos fatores.

\begin{tabular}{cccc}
\hline Fator & Autovalores & Porcentagem & Porcentagem acumulada \\
\hline Fator 1 & 0,3656 & 25,58 & 25,58 \\
Fator 2 & 0,2980 & 20,85 & 46,43 \\
Fator 3 & 0,2770 & 19,38 & 65,81 \\
Fator 4 & 0,2537 & 17,75 & 83,56 \\
Fator 5 & 0,2349 & 16,44 & 100,00 \\
\hline
\end{tabular}

Fonte: Resultado da pesquisa a partir do software IRaMuteq. Elaboração própria (2020).

A Análise Fatorial de Correspondência (AFC), ainda que com sua relativa complexidade, permite uma melhor visibilidade, o que facilita a análise e demonstra a disposição dos elementos do corpus em suas respectivas esferas lexicais e 
semânticas. Tendo essa análise como base, é possível constatar que quanto mais próximo as classes de artigos estiverem umas das outras, mais os assuntos tratados possuem discursos relacionados. Por conseguinte, é evidente que algumas palavras dos artigos de todas as classes estão próximas, quando não, emaranhadas entre si. Demostrando assim, que a maioria dos trabalhos tem discursos relacionados um com o outro e que se pode dar destaque para a proximidade das classes de artigos 5 e 6 tanto quanto às classes 1 e 4 (vide Figura 3). No plano fatorial bidimensional, conforme explicitado por Klamt e Santos (2021), encontram-se as aproximações e/ou distanciamentos entre os vocábulos de cada classe, de acordo com a disposição nos quadrantes.

Figura 3: Análise fatorial de correspondência (AFC).

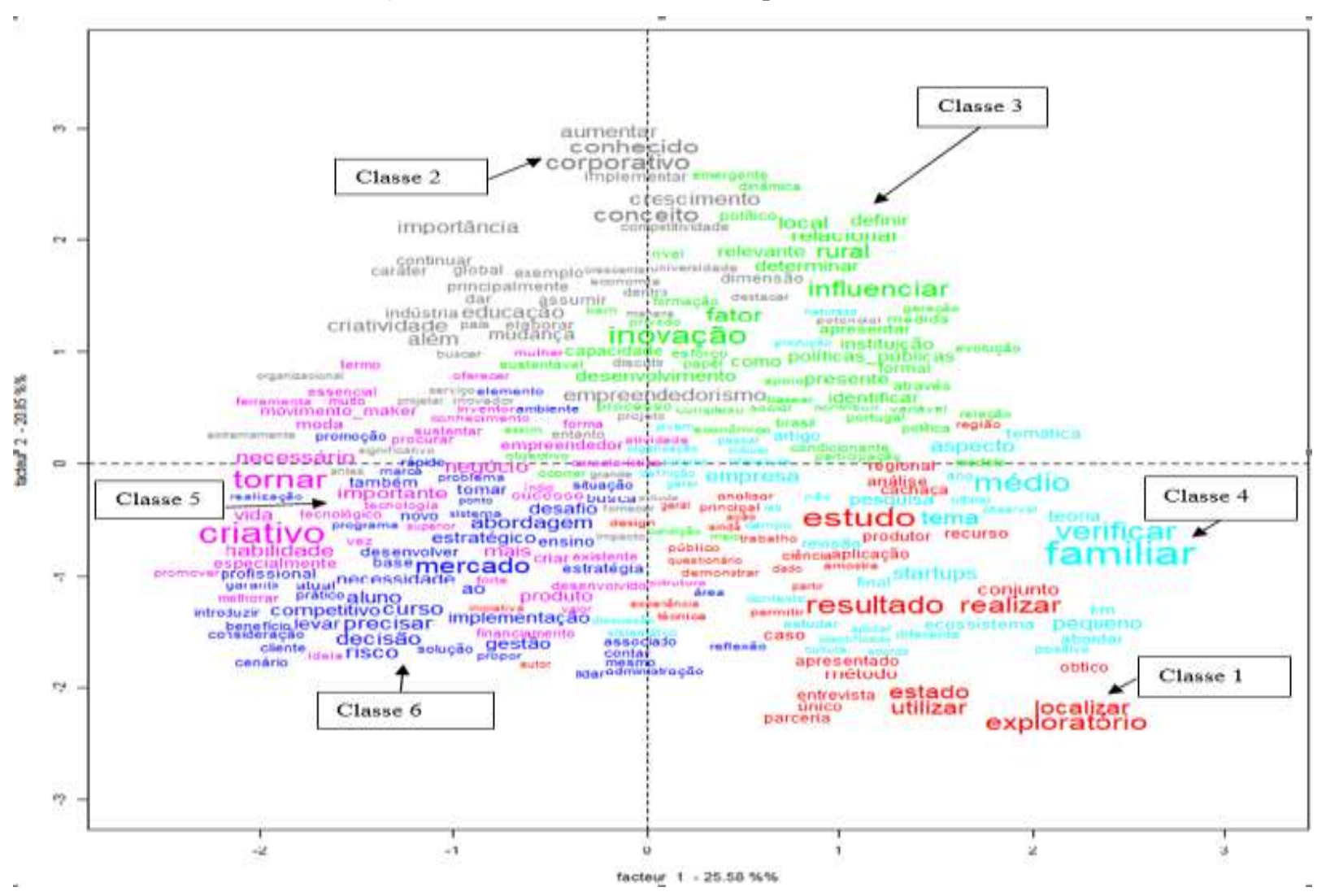

Fonte: Resultado da pesquisa a partir do software IRaMuteq. Elaboração própria (2020).

Destarte, nessa análise fatorial, podem-se utilizar as informações contidas para futuros estudos, visto que, identificamse gaps teóricos presentes no corpus textual como, por exemplo: relacionar o conhecimento corporativo hoje já existente nas empresas para auxiliar as empresas que utilizam a gestão familiar em seus empreendimentos; ou então estudos que confrontem a criatividade e sua relação com o sucesso de empreendimentos inovadores. Deve-se ressaltar, dentro da complexidade inerente à $\mathrm{AFC}$, que os vocábulos que estão expostos no mapa fatorial bidimensional são agrupados conforme seu significado semântico. Esse mapa fatorial é consolidado, portanto, por meio dos vocábulos mais frequentes e relevantes dentro das classes que formam os dois eixos fatoriais, que são os que retêm maior quantidade de informações (Chaib \& Chaib Filho, 2015). Dessa maneira, o fator 1 (F1), na linha horizontal, é formado pelas palavras ou expressões mais significativas evocadas nos textos analisados e que explicam, em conjunto, $25,58 \%$ da variância. $\mathrm{O}$ mesmo processo ocorre para o fator 2 (F2), que explica os $20,85 \%$ da variância.

A AFC reforça, consequentemente, as ligações apresentadas pela análise CHD, mas apresentadas, agora, pelos seus principais vocábulos num plano gráfico (Nascimento \& Menandro, 2006). Nesse caso, pode-se afirmar, por exemplo, que os 
principais vocábulos dos artigos que formam as classes 4 e 1 mesclam-se entre eles, mostrando a correlação existente entre eles. Da mesma forma, pode-se afirmar que acontece com os vocábulos das classes 6 e 5. Assim, constata-se que quanto mais próximas as palavras dispostas no plano, mais elas remetem as mesmas coisas, ou seja, correlacionam-se entre si, contudo em magnitudes diferentes (Nascimento \& Menandro, 2006).

O grande questionamento que fica na literatura é como ocorreu a AFC do software IRaMuteQ. Então, para esclarecer o processo analítico de elaboração do dendrograma AFC, deve-se dizer que o mesmo somente foi possível após a consideração das análises das palavras que obtiveram frequência igual ou maior que a frequência média apurada, $\chi^{2}$ maior ou igual a 15 e $p$ de significância $\leq 0,0001$. Dessa forma, é possível observar as palavras que obtiveram maior porcentagem relativa à frequência média com a análise do resultado do dendrograma. Analisando a Tabela 3 condensada de todos os vocábulos que formam, significativamente, cada classe, pode-se constatar que cada classe foi caracterizada pelas palavras mais importantes sendo seguidas por sua devida classe. Essa tabela evidencia, portanto, o percentual de uso (\%), o resultado do teste qui-quadrado $\left(\chi^{2}\right)$ e as quatro principais palavras que forma as seis classes. Segundo Klant e Santos (2021), o teste qui-quadrado informa o maior grau de significância estatística das palavras em cada classe identificada, o que mostra a forte relação existente na própria classe. Conforme Camargo e Justo (2013), quanto mais elevado for o valor do $\chi^{2}$ de uma palavra específica do corpus, mais representativa será a palavra. O software divide, ainda, o corpus em tantas classes quantas forem as associações resultantes do cálculo do $\chi^{2}$ de cada item lexical.

Tabela 3: Os quatro principais vocábulos estatisticamente significativos em cada cluster do corpus textual

\begin{tabular}{|c|c|c|c|}
\hline Palavra & Porcentagem (\%) & $\chi^{2}$ & $\mathbf{p}$ \\
\hline \multicolumn{4}{|c|}{ CLASSE $1(14,5 \%)$} \\
\hline Estudo & 46,67 & 30,99 & $<0,0001$ \\
\hline Resultado & 60,00 & 27,75 & $<0,0001$ \\
\hline Realizar & 75,00 & 24,95 & $<0,0001$ \\
\hline Exploratório & 100,00 & 24,26 & $<0,0001$ \\
\hline \multicolumn{4}{|c|}{ CLASSE $2(13,2 \%)$} \\
\hline Corporativo & 71,43 & 21,65 & $<0,0001$ \\
\hline Conhecido & 80,00 & 20,09 & $<0,0001$ \\
\hline Conceito & 80,00 & 20,09 & $<0,0001$ \\
\hline Crescimento & 66,67 & 15,55 & $<0,0001$ \\
\hline \multicolumn{4}{|c|}{ CLASSE $3(20,1 \%)$} \\
\hline Inovação & 43,64 & 28,91 & $<0,0001$ \\
\hline Influenciar & 87,50 & 23,79 & $<0,0001$ \\
\hline Fator & 57,14 & 20,62 & $<0,0001$ \\
\hline Rural & 100,00 & 20,49 & $<0,0001$ \\
\hline \multicolumn{4}{|c|}{ CLASSE $4(11,9 \%)$} \\
\hline Familiar & 100,00 & 45,94 & $<0,0001$ \\
\hline Verificar & 100,00 & 30,23 & $<0,0001$ \\
\hline Médio & 83,33 & 30,20 & $<0,0001$ \\
\hline Tema & 66,67 & 17,74 & $<0,0001$ \\
\hline \multicolumn{4}{|c|}{ CLASSE 5 (19,5\%) } \\
\hline Mercado & 66,67 & 21,23 & $<0,0001$ \\
\hline Abordagem & 66,67 & 16,63 & $<0,0001$ \\
\hline Decisão & 100,00 & 15,67 & $<0,0001$ \\
\hline Precisar & 100,00 & 15,67 & $<0,0001$ \\
\hline \multicolumn{4}{|c|}{ CLASSE $6(20,8 \%)$} \\
\hline Criativo & 90,91 & 38,40 & $<0,0001$ \\
\hline Tornar & 88,89 & 29,27 & $<0,0001$ \\
\hline Habilidade & 83,33 & 16,19 & $<0,0001$ \\
\hline Necessário & 83,33 & 16,19 & $<0,0001$ \\
\hline
\end{tabular}

Fonte: Resultado da pesquisa a partir do software IRaMuteq. Elaboração própria (2020). 
Os vocábulos da classe 1, que corresponde a 14,5\% do corpus textual, apresentam as palavras de maior significado e que aparecem com mais frequência sendo: "Estudo", "Resultado", "Realizar" e "Exploratório". A classe 2 representa 13,2\% do corpus e as palavras que apareceram com mais frequência e maior significância no texto foram: "Coorporativo", "Conhecido", "Conceito" e "Conhecimento". A classe 3 apresenta 20,1\% do corpus analisado, cujas palavras mais frequentes são: "Inovação", "Influenciar", "Fator" e "Rural". Na classe 4 tem-se 11,9\% do corpus, cujos vocábulos de maior significância e frequência foram: "Familiar", "Verificar", "Médio" e "Tema”. Já os vocábulos da classe 5, que corresponde a 19,5\% do corpus textual, apresentam as palavras de maior significado e que apareceram com mais frequência sendo: "Mercado", "Abordagem", "Decisão" e "Precisar". A classe 6 apresenta 20,8\% do corpus analisado, cujas palavras mais frequentes são: "Criativo", "Tornar", "Habilidade" e "Necessário".

O software IRAMUTEQ oferece, ainda, a análise de similitude que possibilita o estudo e análise dos vocábulos não mais somente por apresentar conexões entre as classes de artigos, mas, apresentando agora, a conexão entre as próprias palavras em forma de rede, sendo assim, uma forma eficaz de mostrar esses dados é facilitando a análise por deixar a leitura de forma intuitiva (Figura 4). Os resultados do corpus, então, mostram que, no conjunto dos textos analisados, existirá um único nódulo que, por sua vez, se relacionará aos demais vocábulos identificados do corpus textual, que estarão ligados por linhas mais grossas (maior relação existente) e por linhas mais finas, que ajudaram no reforço do tema estudado (Marchand \& Ratinaud, 2012).

Figura 4: Análise de similitude do corpus textual.

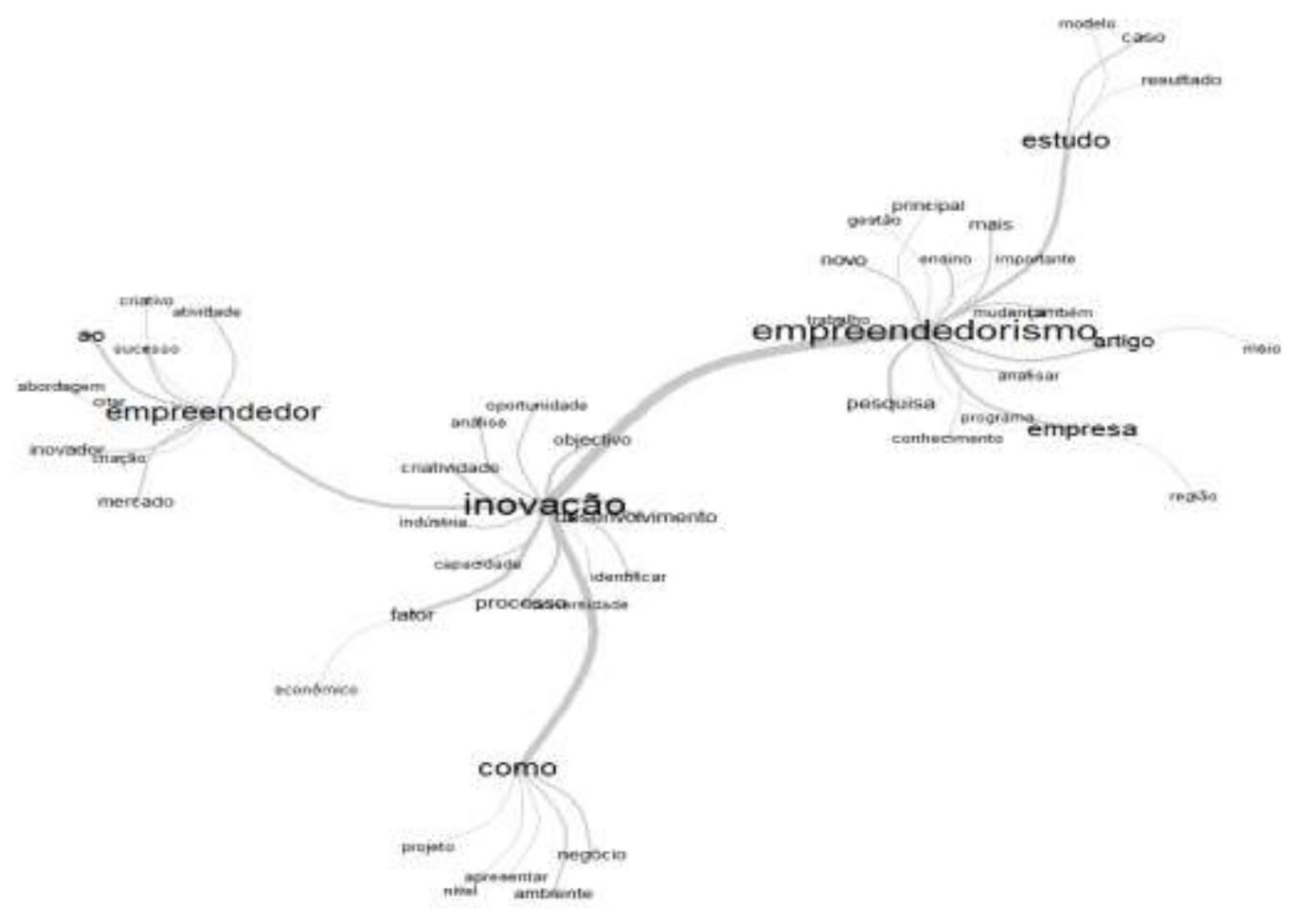

Fonte: Resultado da pesquisa a partir do software IRaMuteq. Elaboração própria (2020).

Desta maneira, observam-se as palavras centrais e suas ramificações que, nessa situação do estudo, foram: os vocábulos "inovação" e "empreendedorismo" como elementos centrais para formar a rede de palavras, e é interessante ressaltar que a o vocábulo "empreendedor" se liga à palavra "inovação" e não a palavra "empreendedorismo" como era de se esperar. 
Isso mostra que a inovação está ligada fortemente ao empreendedor, mais até do que as relações dele com as ramificações do próprio empreendedorismo. Podem-se observar, também, como elementos em foco, a questão "desenvolvimento", "empresa" e "inovador". Vale ressaltar que foram consideradas as palavras que obtiveram mais de $10 \%$ de participação no corpus textual para a formação desta árvore de ligações dos vocábulos.

\section{Conclusão}

Este estudo teve como objetivo realizar uma revisão sistemática sobre o empreendedorismo e a inovação a partir dos trabalhos científicos publicados em periódicos brasileiros e internacionais entre os anos 2015 e 2019 sob a perspectiva da análise lexical. Em face do exposto, ambos, a resposta do estudo e o objetivo foram alcançados após a análise dos dados textuais executados no software IRAMUTEQ, no qual se destacou as seguintes contribuições:

$\mathrm{O}$ corpus foi fragmentado em seis clusters e em dois sub-corpus (R1 e R2) sendo que o sub-corpus R1 foi dividido em mais dois sub-corpus (RIA e RIB). A classe 1, pertence ao sub-corpus R1A, representa $14,5 \%$ de participação no total do corpus textual, a classe 4 corresponde a $11,9 \%$ e, juntas, representam $26,4 \%$ do total do corpus. A classes 2, representa $13,2 \%$ do corpus textual e a classe 3 representa 20,1\%, sendo assim do sub-corpus R1B e representam, ao todo, 33,3\% do corpus textual. A classe 5, pertence ao sub-corpus R2 assim como a classe 6, representando cada uma, respectivamente, 19,5\% e 20,8\% do total do corpus. Observa-se, ainda, que a combinação dos clusters 2 e 3 tendem a possuir uma maior conexão por estarem no mesmo ramo do dendrograma, o mesmo ocorre com as classes 5 e 6 .

Os resultados do processamento dos dados coletados revelam que os estudos dos autores da classe 1 abordam a temática inovação e gestão de resultados e do empreendedorismo no desenvolvimento social. Na classe 2, os autores dos artigos agrupados trabalharam na forma como os conhecimentos das áreas de inovação e empreendedorismo são abordados. Estudos de caso sobre o empreendedorismo rural e a inovação no setor de cosméticos é observado nos trabalhos presentes na classe 3. Na classe 4, o grupo de artigos agrupados tratam da gestão do conhecimento e do desenvolvimento da inovação e do empreendedorismo no âmbito acadêmico. Já na Classe 5, podemos observar que os assuntos abordados giram em torno dos desafios, oportunidades e do processo criativo de inovar e empreender. E por fim, na classe 6 vemos a importância da gestão estratégica e busca de oportunidades para o desenvolvimento dos temas desse trabalho.

Constatou-se que é evidente que algumas palavras dos artigos de todas as classes estão próximas. Demostrando assim, que a maioria dos trabalhos tem discursos relacionados um com o outro e que podemos dar destaque para a proximidade das classes de artigos 5 e 6 tanto quanto às classes 1 e 4. Com os resultados, foi possível apontar conexões entre os vocábulos "inovação" e "empreendedorismo" como elementos centrais para formar a rede de palavras, e é interessante ressaltar que o vocábulo "empreendedor" se mostra um ramo da palavra "inovação" e não da palavra "empreendedorismo" como era de se esperar.

Desse modo, neste trabalho, podemos utilizar as informações contidas nele para futuros estudos, visto que, identificam-se gaps teóricos presentes no corpus textual. Uma barreira que se apresentou na análise refere-se ao número de trabalhos analisados, que podem ser expandidos não somente observando as publicações em periódicos nacionais e internacionais, mas, também, em outras plataformas renomadas de trabalhos acadêmicos, além de artigos apresentados em seminários e congressos nacionais e internacionais.

\section{Referências}

Alves, E. M. S. P \& Júnior, O. F. P. S. (2015). Aplicação da Criatividade para Gerar Projetos de Inovação: O Caso Prático de uma Estratégia Didática. Future Journal. 7(1), $108-131$.

Barboza, R. A. B. \& Faria, F. A. (2015). Inovação em pequena empresa: um estudo com produtores de cachaça. Revista Ciência em Extensão. 11 (2), 38-55. 
Borges, A. F., Brito, M. J. de, Lima, J. B. \& Castro, C. L. C. (2016). Empreendedorismo em empresas familiares: a pesquisa atual e os desafios futuros. Revista de Administração Mackenzie. 17(2), 93-121.

Brasil, M. V. O., Oliveira, F. C. de, Tassigny, M. M. \& Pompeu, R. M. (2015). Inovações sustentáveis em projetos de responsabilidade social. Revista Eletrônica Gestão \& Sociedade. 9(22), 810 - 831.

Bujor, A. \& Avasilcai, S. (2016). The Creative Entrepreneur: a Framework of Analysis. Procedia - Social and Behavioral Sciences, 221,21 - 28.

Camargo, B. V. \& Justo, A. M. (2013). IRAMUTEQ: um software gratuito para análise de dados textuais. Temas em Psicologia. 21(2), 513-518.

Chaib, F. \& Chaib Filho, H. (2015). Aplicação da Análise Fatorial de Correspondências na Avaliação da Influência do Gesto na Performance Musical em Percussão. Proceeding Series of the Brazilian Society of Applied and Computational Mathematics. 3(1), 1-7.

Collins, P. K. (2015). Building a Local Design And Entrepreneurship Ecosystem. Procedia Technology, 20, 258- 262.

Damian, D. \& Manea, C. (2019). Causal recipes for turning fin-tech freelancers into smart entrepreneurs. Journal of Innovation \& Knowledge, 4, 196-201.

Delattre, L., Chanel, O., Livenais, C. \& Napoléone, C. (2015). Combining discourse analyses to enrich theory: The case of local land-use policies in South Eastern France. Ecological Economics, 113, 60-75.

Erenkol, H. A. D. \& Oztas, Y. B. B. (2015). Entrepreneurial Brand. World Conference on Technology, Innovation and Entrepreneurship. Procedia - Social and Behavioral Sciences, 195, 1138 - 1145.

Faria, M. F., B. \& Fonseca, M. V. A. (2014). Cultura de Inovação: Conceitos e Modelos Teóricos. Revista de administração Contemporânea. 18(4), 373-396.

Gallas, J. C., Vargas, S. M. L. \& Lenzi, F. C. (2015). A indústria de cosméticos sob a perspectiva do empreendedorismo e da capacidade dinâmica. Revista Eletrônica de Estratégia \& Negócios. 8(1), 170-198.

Galvão, T. F.\& Pereira, M. G. (2014). Revisões sistemáticas da literatura: passos para sua elaboração. Epidemiologia e Serviços de Saúde. 23(1), 183-184.

Harkema, S. \& Popescu, F. (2015). Entrepreneurship education for adults: a case-study. Procedia - Social and Behavioral Sciences. 209,213 - 220.

Hashimoto, M. (2006). Espírito Empreendedor nas Organizações: Aumentando a competitividade através do intraempreendedorismo. Saraiva.

Hisrich, R. D. \& Peters, M. P. (2004). Empreendedorismo. (5a ed.), McGraw- Hill.

Holm, E. J. V. (2015). World Conference on Technology, Innovation and Entrepreneurship. Makerspaces and Contributions to Entrepreneurship. Procedia Social and Behavioral Sciences, 195, $24-31$.

Howkins, J. (2013). Economia Criativa: Como ganhar dinheiro com ideias criativas. M.Books.

Iskender, E. \& Bati, G. B. (2015). Comparing Turkish Universities Entrepreneurship and Innovativeness Index's Rankings with Sentiment Analysis Results on Social Media. Procedia - Social and Behavioral Sciences, 195, $1543-1552$.

Jha, S. K. (2018). Entrepreneurial ecosystem in India: Taking stock and looking ahead. Indian Institute of Management Bangalore, Bangalore, Karnataka, India.

Jones, C. I. (1998). Introdução à Teoria do Crescimento Econômico. Ed. Campus.

Klamt, L. M. \& Santos, V. S. dos. (2021). O uso do software IRaMuteQ na análise de conteúdo - estudo comparativo entre os trabalhos de conclusão de curso do ProfEPT e os referenciais do Programa. Research, Society and Development. 10(4), 1-15.

Koche, J. C. (2011). Fundamentos de metodologia científica. Vozes.

Lami, J., Silva, F. \& Vaz, E. (2015). A governação em SI: o caso da gestão das convenções e acordos de saúde do Algarve. RISTI - Revista Ibérica de Sistemas e Tecnologias de Informação, 15, 69-81.

Laurikainen, M., Silva, F. L. da, Schlemper, P. F., Soares, J. W. B. \& Melo, L. H. M. de. (2018). Educação em Empreendedorismo: o que podemos aprender dos exemplos brasileiros e finlandeses? Revista Ibero-Americana de Estudos em Educação, 13(1), 337-360.

Leandro, C. R. \& Amato Neto, J. (2015). Uma abordagem cognitiva sobre o processo de institucionalização de sistemas locais de produção e inovação. Production. 25(2), 428-440

Leite, A. \& Oliveira, F. (2007). Empreendedorismo e Novas Tendências. Estudo EDIT VALUE Empresa Junior, 5,(1-35). www.foreigners.textovirtual.com/empreendedorismo-e-novastendencias-2007.

Marchand, P. \& Ratinaud, P. (2012). L'analyse de similitude appliqueé aux corpus textueles: les primaires socialistes pour l'election présidentielle française. Actes des lleme Journées internationales d'Analyse statistique des Données Textuelles, Belgica, 687-699.

Medeiros, S. A. (2017). Avaliação do ambiente psicossocial propício ao desenvolvimento do empreendedorismo inovador: os valores e as motivações dos micro empreendedores da cidade de Penedo - Alagoas. Vianna Sapiens. 5(2), 312-335.

Metcalfe, J. S. (2003). The entrepreneur and the style of modern economics. In: Seminário Brazil on development, UFRJ.

Miguez, V. B.\& Lezana, A. G. R. (2018). Empreendedorismo e inovação: a evolução dos fatores que influenciam o empreendedorismo corporativo. Navus. $8(2), 112-132$. 
Momete, D. C. (2015). Joining economic and engineering perspectives - a tool for successful entrepreneurs. The 6th International Conference Edu World 2014 "Education Facing Contemporary World Issues". Procedia - Social and Behavioral Sciences, 180, 395 - 400.

Moreira, P. A. (2010). Contexto de empreendedorismo. Elsevier.

Mostagi, N. C., Pires, L. L., Mahnic, C. L. P. \& Santos, L. M. L. dos. (2019). Banco Palmas: inclusão e desenvolvimento local. Revista Interações. 20(1), 111124.

Moura, L. K. B., Sousa, Y. T. C. S., Marcaccini, A. M., Piagge, C. S. L. D., Alves, M. S. C. F. \& Moura, M. E. B. (2014). Produção Científica sobre Saúde Bucal de Idosos no Brasil. Revista Interdisciplinar. 7(4), 179-188.

Nascimento, A. R. A., Menandro, P. R. M. (2006). Análise lexical e análise de conteúdo: uma proposta de utilização conjugada. Estudos e pesquisas em Psicologia, Rio de Janeiro. 6(2), 72-88.

Natário, M. M., Braga, A. M. \& Fernandes, G. P. (2018). Determinantes do desempenho empreendedor e inovador nas regiões trans fronteiriças. INNOVAR. $28(70), 39-54$.

Niwa, T. H. (2017). Inovação e empreendedorismo à luz de teorias de políticas públicas. Revista de Políticas Públicas. 21(2), 855-873.

Niwa T. H. (2018). Exercício de análises de políticas públicas: o Programa Estratégico para o Empreendedorismo e Inovação do Governo de Portugal (Programa +e+i). Revista Brasileira de Políticas Públicas e Internacionais. 3(2), 29-58.

Oliveira, A. G. M. de, Melo, M. C. O. L. \& Muylder, C. F. de. (2016). Educação Empreendedora: O Desenvolvimento do Empreendedorismo e Inovação Social em Instituições de Ensino Superior. Revista Administração em diálogo (RAD). 18(1), 29-56.

Pinchot, G. \& Pellman, R. (2004). Intraempreendedorismo na Prática: um guia de inovação nos negócios. Tradução Márcia Nascentes. Elsevier.

Prodanov, C. C. \& Freitas, E. C. de. (2013). Metodologia do trabalho científico: métodos e técnicas da pesquisa e do trabalho acadêmico. (2a ed.), Novo Hamburgo: Feevale.

Steenbock, W., et al. (Organizador). (2013). Seoane, C. E.; Froufe, L. C. M. (Colaboradores). Agrofloresta, Ecologia e Sociedade. Curitiba, Kairós, 422 p.

Schumpeter, J.A. (1997). Teoria do desenvolvimento econômico: uma investigação sobre lucros, capital, crédito, juro e o ciclo econômico. Edição original de 1911, Nova Cultural, São Paulo (Os Economistas).

Sen, A. (1999). Desenvolvimento como Liberdade. Ed. Companhia das Letras.

Severo, E. A., Guimarães, J. C. F., Serafin, V. F. \& Vanin, M. S. (2019). Vamos Expandir um Negócio Inovador? Caso de Ensino. Revista de Administração, Sociedade e Inovação. 5(1), 77-90.

Smallman, M. (2016). Public Understanding of Science in turbulent times III: Deficit to dialogue, champions to critics. Public Understanding of Science. 25(2), 186-197.

Soloducho-Pelc, L. (2015). Searching for opportunities for development and innovations in the strategic management process. 4th International Conference on Leadership, Technology, Innovation and Business Management. Procedia - Social and Behavioral Sciences, 210,77 - 86.

Sousa, B. M. (2016). A dinâmica diferenciadora e o processo de criação na gestão de destinos turísticos. Revista Brasileira de Pesquisa em Turismo, $10,3-17$.

Teixeira, T. S., Andrade, D. M., Alcântara, V. C. \& Oliveira, N. K. de. (2019). Inovação e empreendedorismo: um caso no setor público. Revista Pretexto. 20(1), 57-71.

Webber, C. C., Nunes, F. P. \& Guimarães, J. C. F. (2016). O posicionamento estratégico como determinante do futuro de uma indústria de móveis: caso de ensino. Produção e Desenvolvimento. 2(3),1-13.

Yunus, M. (2000). O banqueiro dos pobres. Ática.

Yunus, M. (2010). Criando um Negócio Social. Campus. 